Research Paper

\title{
Mechanical Properties and Porosity of Acrylic Cement Bone Loaded with Alendronate Powder
}

\author{
Guo-Xin Qu, Zhi-Min Ying, Chen-Chen Zhao, Shi-Gui Yan, Xun-Zi Cai ${ }^{\bowtie}$ \\ Department of Orthopaedic Surgery, The Second Affiliated Hospital, Zhejiang University School of Medicine, Jiang-Hong Road 1511, Hangzhou, China. \\ $\square$ Corresponding author: Xun-Zi Cai, MD, Department of Orthopaedic Surgery, The Second Affiliated Hospital, Zhejiang University School of Medicine, \\ Jiang-Hong Road 1511, Hangzhou, China. E-mail: 2506053@zju.edu.cn \\ ( ) Ivyspring International Publisher. This is an open access article distributed under the terms of the Creative Commons Attribution (CC BY-NC) license \\ (https://creativecommons.org/licenses/by-nc/4.0/). See http://ivyspring.com/terms for full terms and conditions.
}

Received: 2018.06.09; Accepted: 2018.08.08; Published: 2018.09.07

\begin{abstract}
Aseptic loosening is the most common complication of joint replacement. Previous studies showed that acrylic bone cement loaded with a commercially-available alendronate powder (APAC) had good promise against wear debris-mediated osteolysis for prevention of aseptic loosening. The purpose of the present study was to investigate the effect of adding alendronate powder to an acrylic bone cement on quasi-static mechanical properties (namely, compressive strength, compressive modulus, tensile strength, and flexural strength), fatigue life, porosity, and microstructure of the cement. The results showed that adding up to $1 \mathrm{wt} . / \mathrm{wt} . \%$ alendronate powder exerted no detrimental effect on any of the quasi-static mechanical properties. However, the fatigue life of APAC decreased by between $\sim 17 \%$ and $\sim 27 \%$ and its porosity increased by between $\sim 5-7$ times compared with corresponding values for the control cement (no alendronate powder added). Fatigue life was negatively and significantly correlated with porosity. Considering that fatigue life of the cement plays a significant role in joint replacement survival, clinical use of APAC cannot be recommended.
\end{abstract}

Key words: Acrylic bone cement; Alendronate; Mechanical properties; Fatigue life; Porosity

\section{Introduction}

Aseptic loosening is the most common complication of joint replacement [1]. Currently, there is no other treatment of aseptic loosening except revision arthroplasty [2]. The effective prevention is critical in the control of aseptic loosening. It has been shown that oral-administered bisphosphonate, especially alendronate, effectively inhibits wear debris-induced osteolysis and reduces the risk of aseptic loosening [3]. However, adverse events, notably, upper gastrointestinal ulcer, and a low bioavailability of $0.7 \%$ were frequently observed with oral-administered alendronate [4]. Furthermore, poor drug compliance in patients compromised the therapeutic efficacy of alendronate [5].

In 1994, Hamish et al. put forward the idea of a bisphosphonate-loaded acrylic bone cement as a local drug delivery system [6]. This proposal is similar to the addition of antibiotic(s) to an acrylic bone cement
[7]. The local high administration of bisphosphonate is achieved through sustained drug elution from the cement $[8,9]$. Our previous in vivo study showed that the local release of alendronate from an acrylic bone cement inhibited wear debris-mediated osteolysis and enhanced the mechanical strength of the host bone in a cemented arthroplasty [10]. The proposed mechanism was that the eluted bisphosphonate stimulated an increase in osteoprotegerin ligand and a decrease in receptor activator of nuclear factor kappa-B ligand [11].

There have been a number of reports on bisphosphonate-loaded acrylic bone cement [12-15]. $\mathrm{Yu}$ et al. [12] found loading liquid pamidronate reduced the bending strength of the cement by $39 \%$. Lewis et al. [13] demonstrated that the fatigue life of the cured cement was reduced by $97 \%$ and $39 \%$ when alendronate was added in liquid form and in the form 
of tablet-ground powder, respectively (both values relative to that for the plain cement). These results were attributed to the interference of the polymerization process by the liquid alendronate and the excipient in the alendronate tablet [12, 13]. Matuszewski et al. [14] found that addition of $60 \mathrm{mg}$ of pamidronate powder to $40 \mathrm{~g}$ of cement did not have a detrimental effect on either the compressive strength or the flexural strength of the cement. Song et al. [15] showed that addition of no more than $500 \mathrm{mg}$ of alendronate powder to $50 \mathrm{~g}$ of cement did not significantly decrease either the compressive strength or the bending strength of the cement. To the best of our knowledge, there are no studies that involve determination of both quasi-static mechanical properties and fatigue life of an acrylic bone cement loaded with the powder of a bisphosphonate.

The purpose of the present study was to determine the effect of adding a commercially-available alendronate powder to an acrylic bone cement (APAC) on the compressive strength, tensile strength, flexural strength, fatigue life, porosity, and microstructure of the cement.

\section{Materials and Methods}

\section{Materials and preparation of test specimens}

The alendronate powder (Merck, Sharp \& Dohme, Hangzhou, China; particle size range of 4.67 $44.21 \mu \mathrm{m}$ and mean $=20.77 \mu \mathrm{m})$ and the powder of the
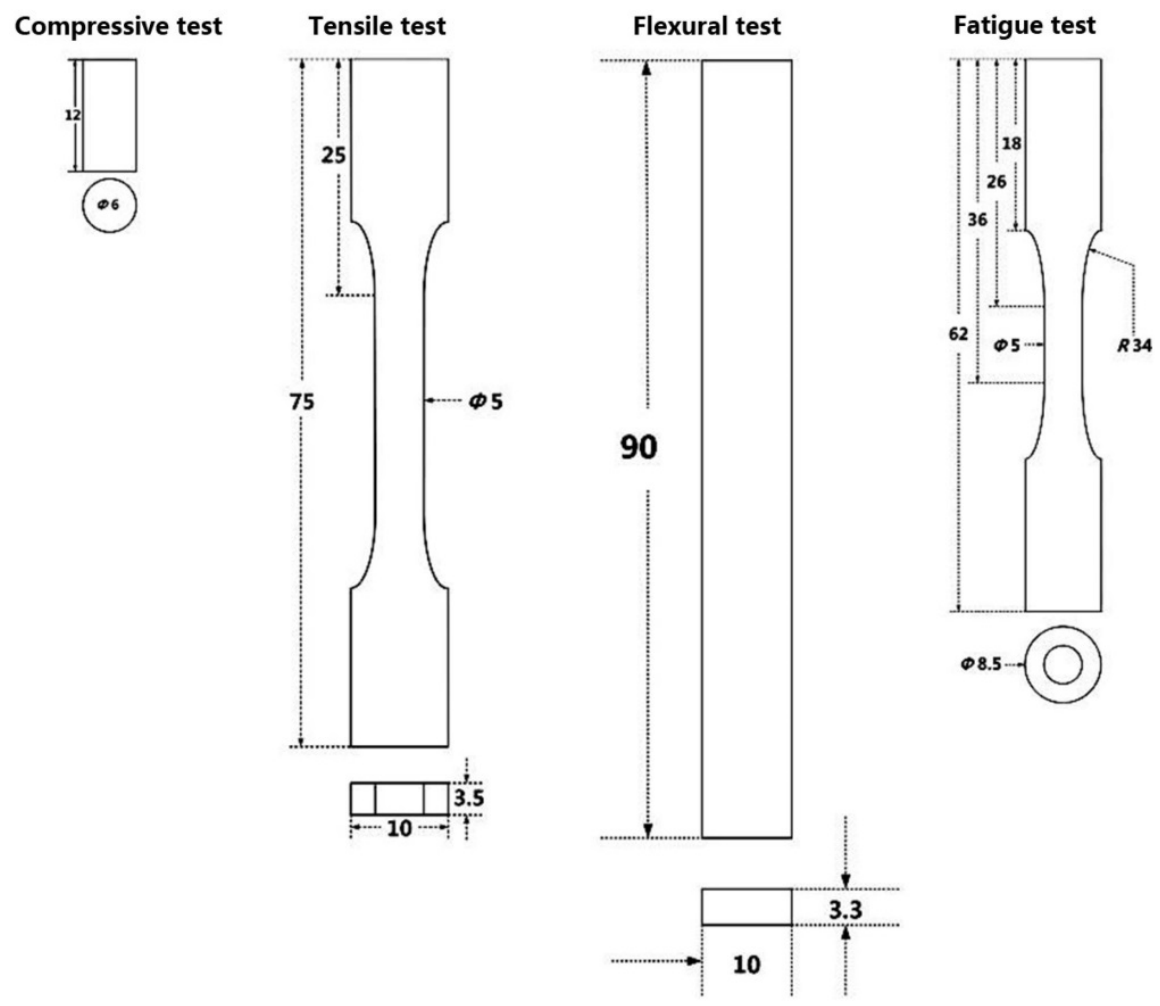

Figure 1. Dimensioned drawings of the specimens used in the mechanical properties tests (All dimensions are in $\mathrm{mm}$ ). bone cement (CMW Endurance; DePuy, London, England) were mixed using the open-bowl technique in ambient laboratory conditions, as described by Lewis et al. [13]. The liquid of the cement was added to the blended powder mixture. After that, the cement dough was injected into different stainless steel molds to produce specimens for different tests (Fig. 1). Then, the cured cement specimens were taken out of the molds and polished with a 600-grit sandpaper. The specimens were examined by visual inspection, digital calipering, high-light exposure, and X-radiography. Specimens were discarded if any of the following problems existed: surface flaw(s) $>0.25$ $\mathrm{mm}$ on the body of the specimen and/or in transition sections; pore size $>1 \mathrm{~mm}$ in diameter within the specimen and/or in transition sections; and any dimension being more than $5 \%$ within its nominal value [13].

\section{Study groups}

The accepted specimens were divided randomly into eight groups based on the alendronate loading [6] and the aging condition of the cured cement (in ambient laboratory atmosphere or immersed in the phosphate buffered saline solution (PBS), $\mathrm{pH} 7.4$ (Gibco Invitrogen Corp, Grand Island, NY) for 30 days) [16]. Thus, the groups were: the atmospheric control group $\left(\mathrm{G}_{\mathrm{A} 0}\right)$, the immersed control group $\left(\mathrm{G}_{\mathrm{I}}\right)$, the atmospheric $0.1 \mathrm{wt} . / \mathrm{wt} . \%$-alendronate group $\left(\mathrm{G}_{\mathrm{A} 0.1}\right)$, the immersed $0.1 \mathrm{wt}$./wt.\%-alendronate group $\left(\mathrm{G}_{10.1}\right)$, the atmospheric $0.5 \mathrm{wt}$./wt. $\%$-alendronate group $\left(\mathrm{G}_{\mathrm{A} 0.5}\right)$, the immersed 0.1 wt./wt.\%-alendronate group $\left(\mathrm{G}_{10.5}\right)$, the atmospheric 1 wt./wt.\%-alendronate group $\left(\mathrm{G}_{\mathrm{A1}}\right)$, and the immersed 1 wt./wt.\%-alendronate group $\left(\mathrm{G}_{11}\right)$.

\section{Mechanical tests}

The compressive strength, compressive modulus, tensile strength, and flexural strength were determined from tests carried out in ambient laboratory conditions (air, at $22 \pm 1{ }^{\circ} \mathrm{C}$ ), in accordance with ASTM F451 [17] $(\mathrm{n}=6-7)$, ISO 527 [18] $(\mathrm{n}=6-8)$, and ISO 5833 [19] ( $\mathrm{n}=6-9)$, respectively. The fatigue tests were conducted in PBS, at $37 \pm 2$ ${ }^{\circ} \mathrm{C}$ [13], in accordance with ASTM F2118 [20], with applied load corresponding to stress of \pm 15 $\mathrm{MPa}$ and frequency of $5 \mathrm{~Hz}(\mathrm{n}=$ 
7). The results of the fatigue tests (number of cycles to fracture $\left(\mathrm{N}_{\mathrm{f}}\right)$ ) were analyzed using the three-parameter Weibull relationship [21-23], leading to values of the minimum or guaranteed fatigue life $\left(\mathrm{N}_{\mathrm{o}}\right)$, the characteristic fatigue life $\left(\mathrm{N}_{\mathrm{a}}\right)$, and the Weibull modulus (m) [21-23]. The fatigue performance index was computed as the Weibull median $\left(\mathrm{N}_{\mathrm{wm}}\right)$ thus [21]

$$
\mathrm{N}_{W M}=\mathrm{N}_{\mathrm{o}}+\mathrm{N}_{\mathrm{a}}(\ln 2)^{1 / \mathrm{m}}
$$

\section{Morphology and porosity of fracture surfaces}

Following a fatigue test, the fracture surface of the specimen was cleaned ultrasonically, dried, sputter-coated with a gold-palladium layer, and inspected at $25.0 \mathrm{kV}$ with a scanning electron microscope (SEM; SIRION 100, FEI, United States) at a magnification of $93 \times$. Five sections of a specimen were selected at random and, then, porosity was determined. This involved using a commercially-available software package (Image-pro plus 6.0, Media Cybernetics, Inc., Silver Spring, MD, USA) to select a region of interest (ROI) within a segment and, then, digitizing it. For each image, the number of pores, the mean pore size, and the number of pixels counted were determined. Porosity $(\mathrm{P})$ was calculated thus [10]

$$
\mathrm{P}=\mathrm{A}_{\mathrm{p}} / \mathrm{A}_{\mathrm{i}}
$$

where $A_{p}$ is the total area occupied by all the pores and $\mathrm{A}_{\mathrm{i}}$ is the area of the whole image.

\section{Statistical analysis}

Quantitative results were expressed as mean \pm standard deviation. Each set of quantitative results was first tested for normality using the variance homogeneity and normal distribution tests. When this was found to be the case, a parametric test of significance of difference in means (one-way analysis of variance) was used. Otherwise, a non-parametric test of significance was used. Intergroup differences were compared with the method of the least significant difference. Regression analyses were performed between $\mathrm{P}$ and each of the quasi-static mechanical properties as well as between $\mathrm{P}$ and $\mathrm{N}_{\mathrm{f}}$ [24]. Statistical significance was denoted if $p<0.05$. Analyses were performed with a commercially-available software package (SPSS 16.0 for Windows; SPSS Inc., Chicago, IL, USA).

\section{Results}

\section{Quasi-static mechanical properties}

The influence of alendronate powder loading (ALN) on compressive strength was not significant (F $=4.177, \mathrm{p}=0.094)$, but immersion in PBS produced a significant reduction in this strength $(\mathrm{F}=7.140, \mathrm{p}=$ 0.0100), and, for each cement group, this strength exceeded the minimum level stipulated in ASTM F451 (70 MPa) (Fig. 2).The same trends were found for (a) compressive modulus in terms of influence of ALN (F $=4.306, \mathrm{p}=0.090)$ and of immersion in PBS ( $\mathrm{F}=$ 15.833, p < 0.001) (Fig. 2); and (b) tensile strength in terms of influence of ALN $(\mathrm{F}=6.732, \mathrm{p}=0.126)$ and of immersion in PBS $(\mathrm{F}=23.125, \mathrm{p}<0.001)$ (Fig. 2). Neither ALN nor immersion in PBS exerted a significant influence on flexural strength $(\mathrm{F}=0.005, \mathrm{p}$ $=0.999$ and $F=15.833, p<0.001$, respectively) (Fig. 2). Furthermore, for each cement group, flexural strength was higher than the minimum level stipulated in ISO 5833 (50 MPa) (Fig. 2).

\section{Fatigue life}

Increase in ALN significantly decreased $\mathrm{N}_{\mathrm{f}}$ and $\mathrm{N}_{\mathrm{WM}}(\mathrm{F}=4.306, \mathrm{p}=0.0090)$ as did immersion in PBS (F $=11.642, \mathrm{p}=0.01)($ Table 1$)$.

Table 1. Summary of the fatigue test results $\left(N_{f}\right)$ and the

\begin{tabular}{|c|c|c|c|c|c|c|}
\hline \multirow{2}{*}{$\begin{array}{l}\text { Alendronate } \\
\text { powder loading }\end{array}$} & \multirow{2}{*}{$\begin{array}{l}\text { Aging } \\
\text { condition }\end{array}$} & \multirow[t]{2}{*}{$\mathrm{N}_{\mathrm{f}}$ (cycles) } & \multicolumn{4}{|c|}{ Weibull Parameters } \\
\hline & & & $\begin{array}{l}N_{o} \\
\text { (cycles) }\end{array}$ & $\begin{array}{l}\mathrm{N}_{\mathrm{a}} \\
\text { (cycles) }\end{array}$ & $\mathrm{m}$ & $\begin{array}{l}\mathrm{N}_{W M} \\
\text { (cycles) }\end{array}$ \\
\hline \multirow[t]{2}{*}{0 wt./wt. $\%$} & Atmosphere & $17724 \pm 5815$ & 10404 & 19232 & 0.74 & 22136 \\
\hline & PBS & $13458 \pm 2713^{a}$ & 9414 & 15301 & 0.72 & 18595 \\
\hline \multirow[t]{2}{*}{0.1 wt./wt. $\%$} & Atmosphere & $13701 \pm 2496^{\mathrm{a}}$ & 8103 & 15550 & 0.46 & 15101 \\
\hline & PBS & $10875 \pm 1923^{a}$ & 8518 & 14472 & 0.97 & 18504 \\
\hline \multirow[t]{2}{*}{0.5 wt./wt. $\%$} & Atmosphere & $12973 \pm 2964^{a}$ & 8955 & 14309 & 1.09 & 19114 \\
\hline & PBS & $10980 \pm 1767 a$ & 8690 & 11127 & 0.76 & 17562 \\
\hline \multirow[t]{2}{*}{1.0 wt./wt. $\%$} & Atmosphere & $13398 \pm 2973^{a}$ & 8604 & 11300 & 0.87 & 16062 \\
\hline & PBS & $11291 \pm 1865^{a}$ & 8349 & 11771 & 0.93 & 16236 \\
\hline
\end{tabular}
calculated Weibull parameters

a Compared with the atmospheric control group, $p<0.05$.

\section{Porosity measures and pore morphology}

While ALN significantly increased pore number for any pore size $(\mathrm{F}=43.463, \mathrm{p}<0.001)$, the influence of immersion in PBS on a given porosity parameter was not significant $(F=0.096, p=0.759)$ (Fig. 3, Table 2 , and Fig. 4). Furthermore, for each cement group, the pores were uniformly distributed from the margin area to the core area of a specimen (Fig. 5).

Table 2. Microstructure parameters of fracture surface of specimens

\begin{tabular}{lllll}
\hline $\begin{array}{l}\text { Alendronate powder } \\
\text { loading (wt./wt. } \%)\end{array}$ & $\begin{array}{l}\text { Aging } \\
\text { condition }\end{array}$ & $\begin{array}{l}\text { Number of } \\
\text { pores }\end{array}$ & $\begin{array}{l}\text { Total pore area } \\
\left(\mathrm{mm}^{2}\right)\end{array}$ & $\begin{array}{l}\text { Porosity } \\
(\%)\end{array}$ \\
\hline 0 & Atmosphere & $3.33 \pm 2.42$ & $0.051 \pm 0.030$ & $0.90 \pm 0.71$ \\
& PBS & $2.86 \pm 1.46$ & $0.062 \pm 0.030$ & $0.90 \pm 0.47$ \\
0.1 & Atmosphere & $87.29 \pm 44.77^{\mathrm{a}}$ & $0.017 \pm 0.010^{\mathrm{a}}$ & $5.33 \pm 1.56^{\mathrm{a}}$ \\
& PBS & $79.29 \pm 26.76^{\mathrm{a}}$ & $0.016 \pm 0.004^{\mathrm{a}}$ & $5.17 \pm 1.12^{\mathrm{a}}$ \\
0.5 & Atmosphere & $75.71 \pm 33.08^{\mathrm{a}}$ & $0.019 \pm 0.007^{\mathrm{a}}$ & $6.03 \pm 1.69^{\mathrm{a}}$ \\
& PBS & $88.57 \pm 25.75^{\mathrm{a}}$ & $0.014 \pm 0.004^{\mathrm{a}}$ & $5.27 \pm 0.58^{\mathrm{a}}$ \\
1 & Atmosphere & $84.14 \pm 31.18^{\mathrm{a}}$ & $0.018 \pm 0.007^{\mathrm{a}}$ & $5.93 \pm 1.28^{\mathrm{a}}$ \\
& PBS & $103.29 \pm 59.13^{\mathrm{a}}$ & $0.017 \pm 0.011^{\mathrm{a}}$ & $6.36 \pm 2.45^{\mathrm{a}}$ \\
\hline
\end{tabular}

aCompared with the atmospheric control group or immersed control group, $p<$ 0.001 . 

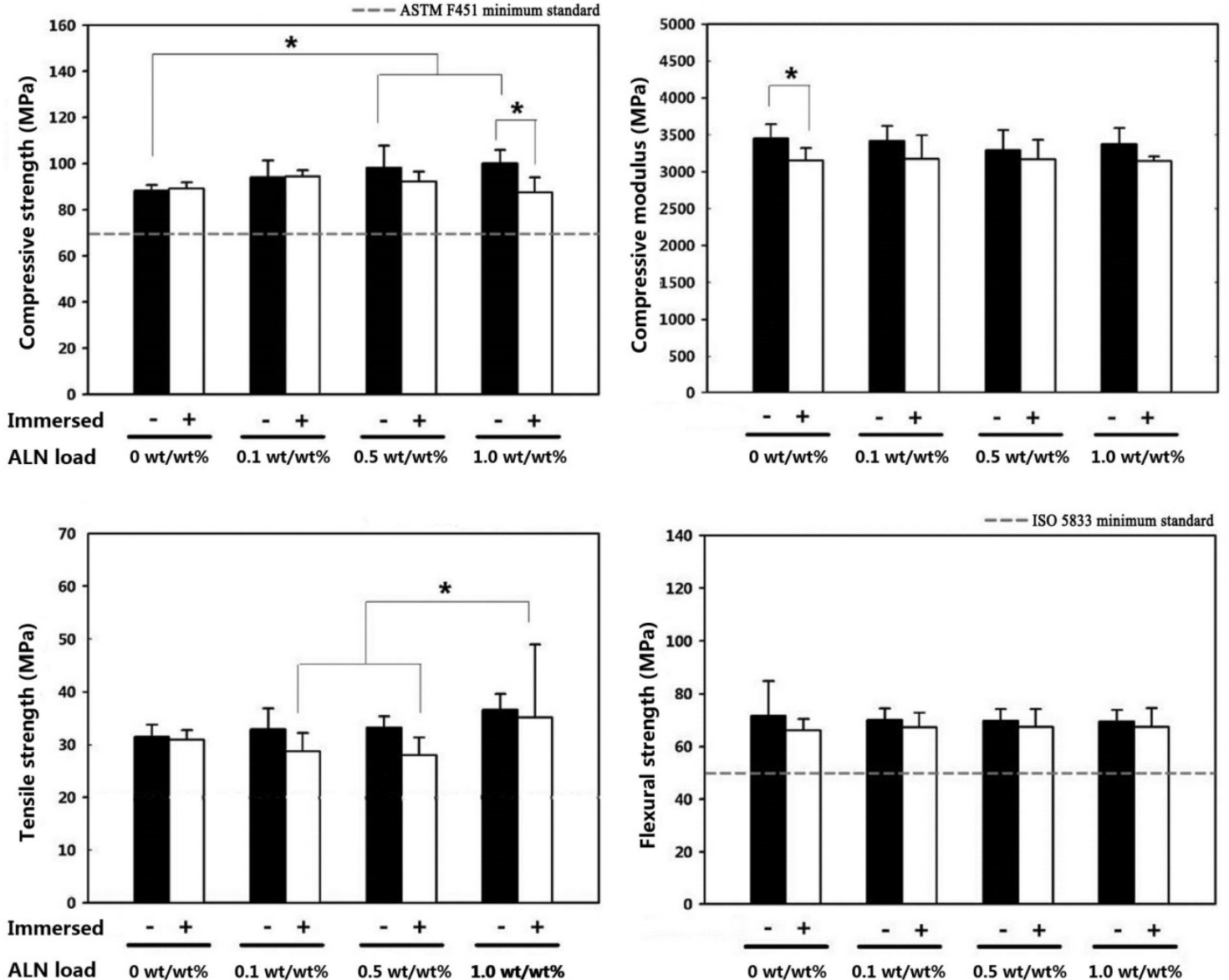

Figure 2. Summary of the quasi-static mechanical properties.

\section{Atmospheric group}

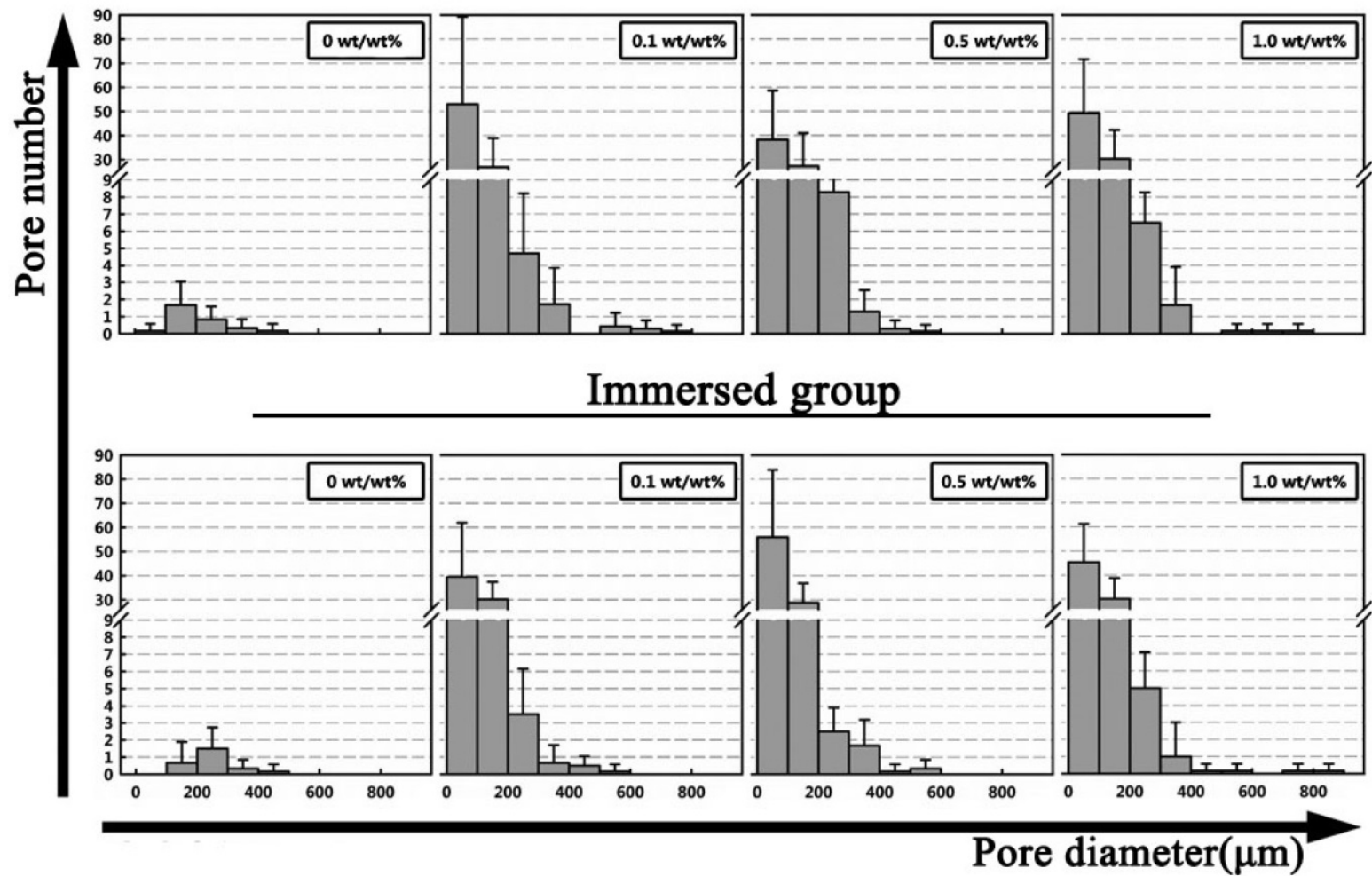

Figure 3. Summary of porosity measures. 

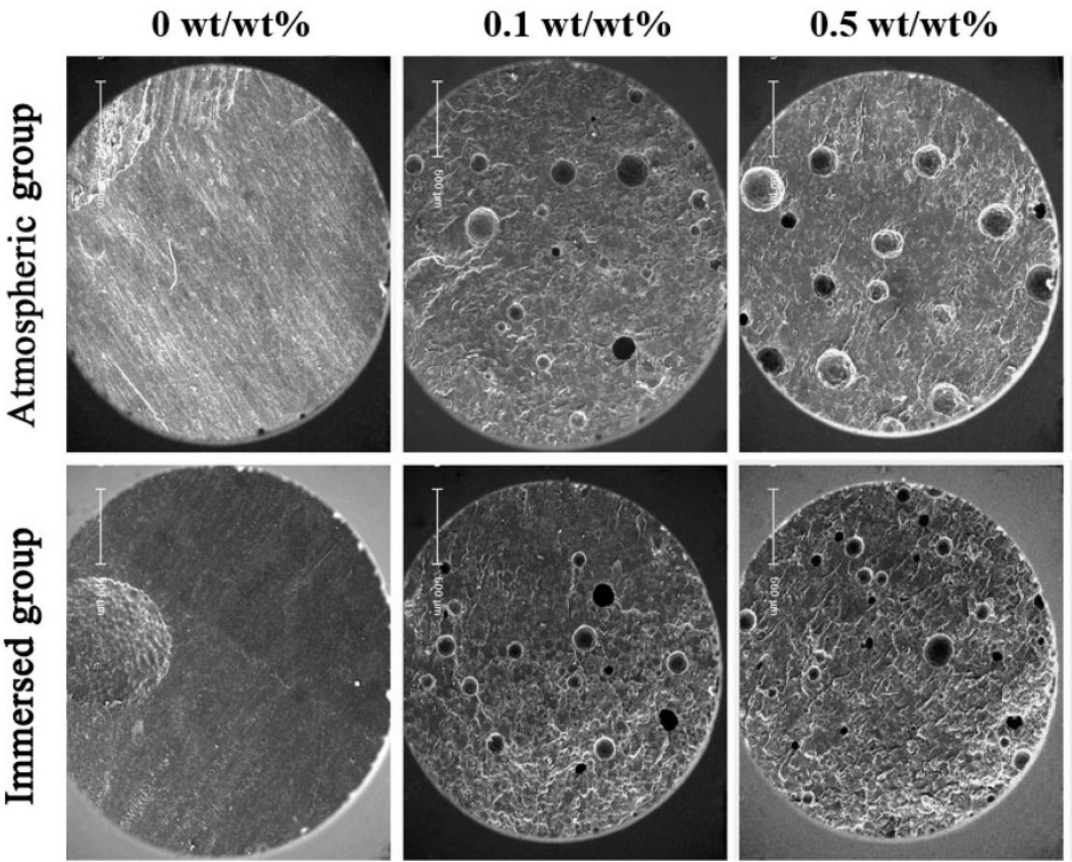

\section{$1.0 \mathrm{wt} / \mathbf{w t} \%$}
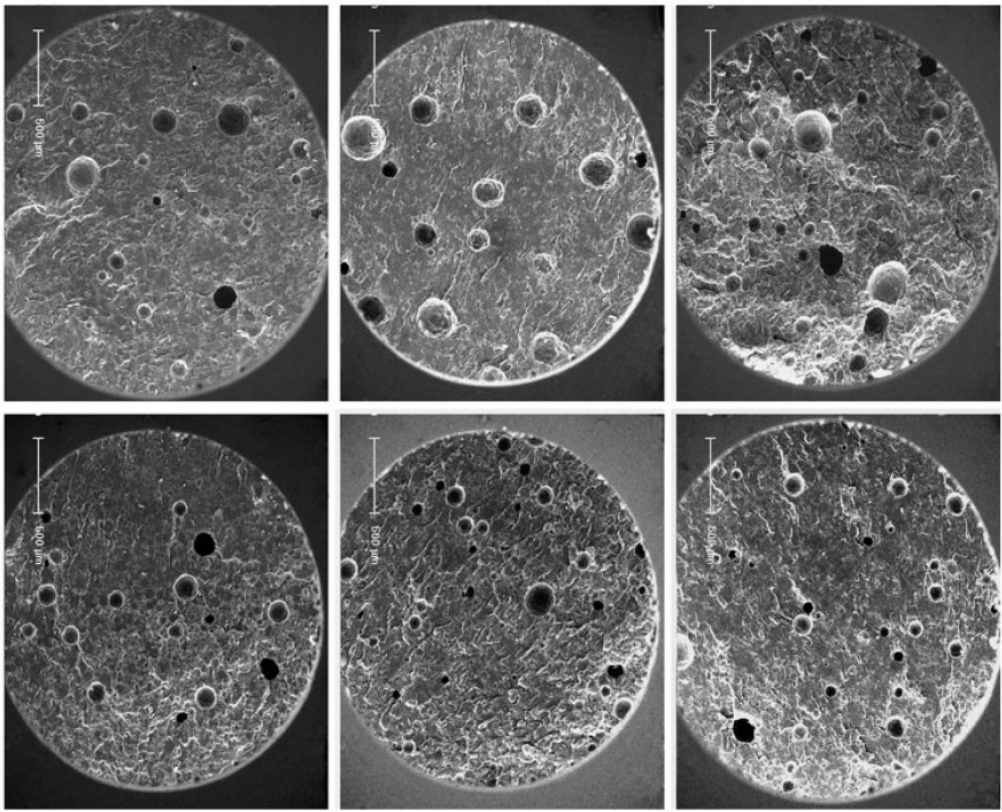

Figure 4. The micrographs of the surfaces of cement specimens after fracture in the fatigue test

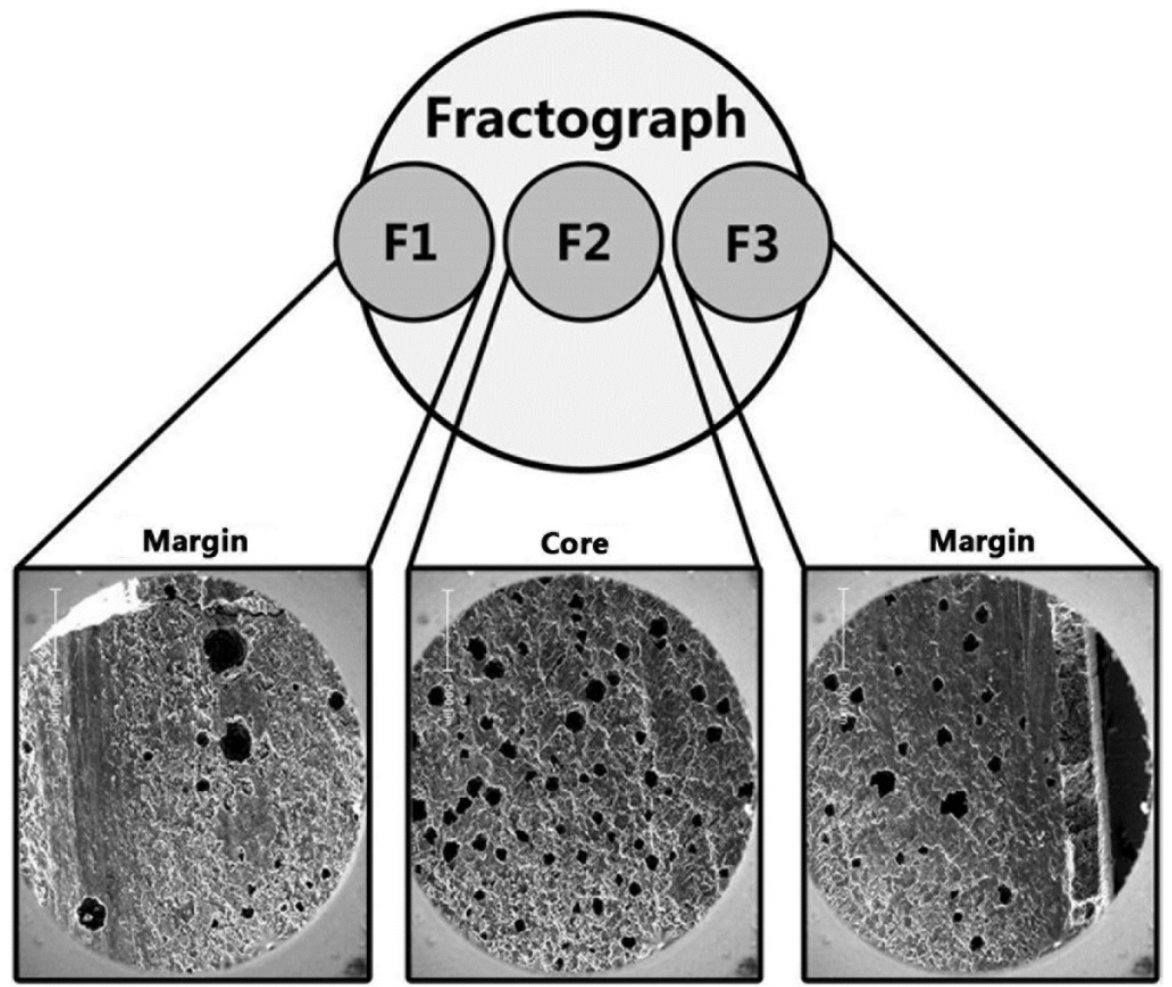

Figure 5. A sample of continuous scanning images of the surfaces of cement specimens after fracture in the fatigue test ( $\mathrm{G}_{\mathrm{Al}}$ cement group specimens).

SEM images showed that $\mathrm{G}_{\mathrm{A} 0}$ and $\mathrm{G}_{\mathrm{I} 0}$ specimens had few pores while specimens in each of the other six alendronate groups had a large number of small particles ranging in size from $10 \mu \mathrm{m}$ to $200 \mu \mathrm{m}$ (Fig. 4). The pores were distributed from the marginal area to the core area of the specimen $\left(\mathrm{G}_{\mathrm{A} 1}\right.$ as an example in Fig. 5).

\section{Correlations}

While the correlation between P and each of the quasi-static mechanical properties was weak and not statistically significant ( $p>0.05)$ (Fig. 6), porosity had a negative and significant correlation with fatigue life $\left(R^{2}=0.562, p<0.01\right)$ (Fig. 7). 

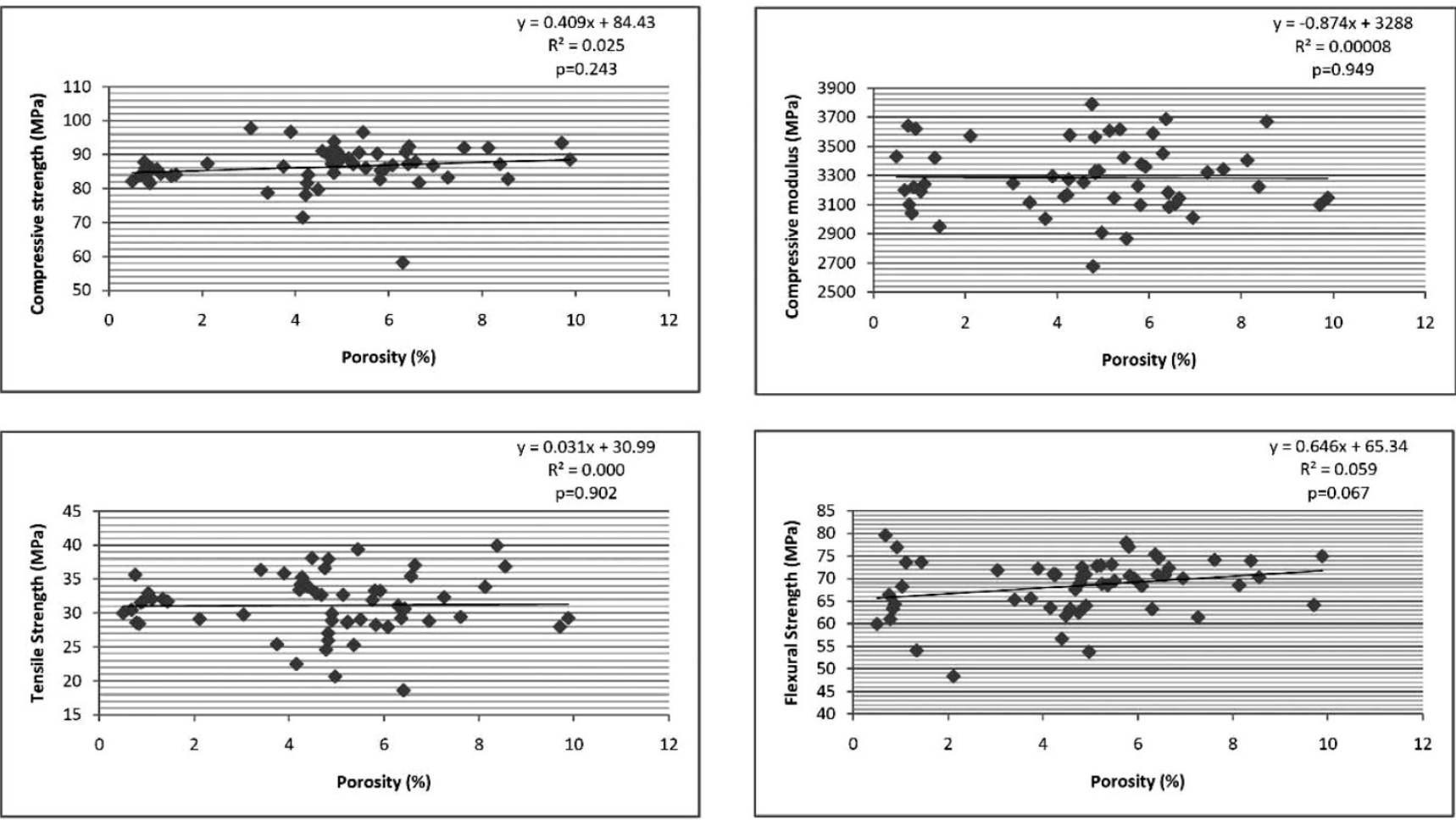

Figure 6. Correlations between porosity and each of the quasi-static mechanical properties.

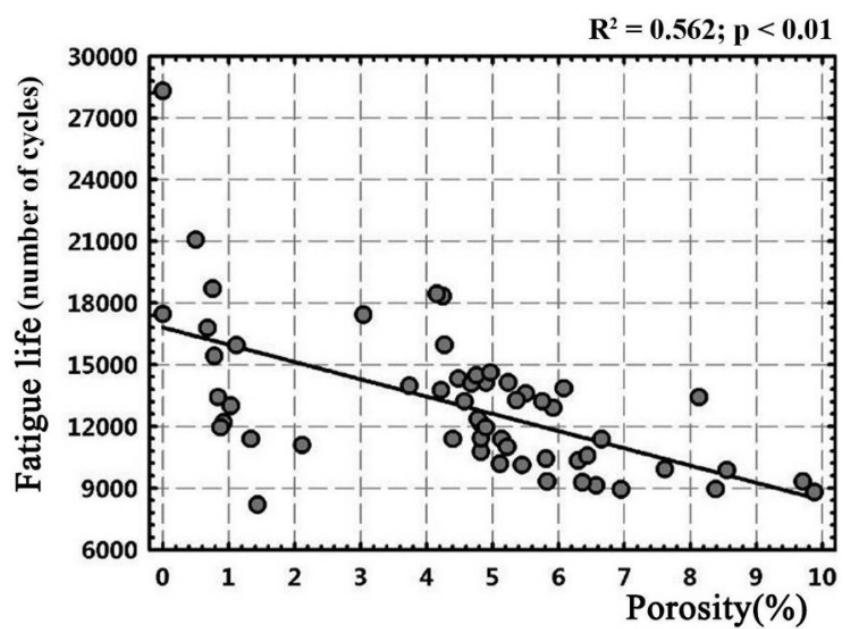

Figure 7. Correlation between porosity and fatigue life $\left(\mathrm{N}_{\mathrm{f}}\right)$.

\section{Discussion}

The mechanical strength of acrylic cement is highly related with the lifespan of the cemented arthroplasty [25]. In previous studies, it was showed that APAC could locally release bisphosphonate, inhibit periprosthetic bone resorption, and enhance the mechanical strength of host bone while avoiding the detrimental effect of oral medication [8-11]. Incorporation of liquid bisphosphonate or tablet-ground alendronate powder significantly decreased the mechanical strength of acrylic bone cement $[12,13]$. APAC may be a better option to maintain the mechanical strength of cement $[14,15]$.
In the present study, we evaluated quasi-static mechanical properties, fatigue life, porosity, and microstructure of APAC.

Our microscopic results demonstrated increased porosity of APAC (relative to that of the control cement) and propose two possible mechanisms for this finding. First, previous studies found that, just like as in the case of an antibiotic-loaded acrylic bone cement, elution of a bisphosphonate powder from a bone cement is low [8]. Since, in the case of APAC, the pores were distributed throughout the fracture surface, we assumed that the large number of pores could not result from powder aggregation. Second, given that the control group and the APAC group specimens were all cured under the same conditions, air inclusion could be eliminated as the reason.

Crack initiation, propagation, and accumulation is the cause of cement fracture. It results in mechanical failure of a cemented arthroplasty [26]. Topoleski et al. [26] and Hoey et al. [24] proposed that, in an acrylic bone cement, pores play a dual role: on one hand, they cause stress concentration and promote crack initiation and propagation, which is detrimental for the cement mantle; but, on the other hand, they divert energy to the surroundings and prevent crack propagation, which is beneficial for the cement mantle. In the present study, a strong and significantly negative correlation was found between fatigue life and porosity, but the correlation between each of the quasi-static mechanical properties and 
porosity was weak and not statistically significant. These findings suggest that in the fatigue test, pores promoted cracks instead of inhibition, which agreed with the conclusions of previous studies [24, 27], but, in a quasi-static test, the effect of crack promotion is offset by that of crack inhibition.

In previous studies, it was shown that liquid bisphosphonate significantly reduced the mechanical strength of acrylic bone cement [12]. It was speculated that liquid bisphosphonate dilutes the substrate and the catalyst of polymerization [12]. The residual monomer acted as a stress riser, which led to mechanical failure. When tablet-ground alendronate powder was added to an acrylic bone cement, fatigue life was reduced by 39\% [13]. The hand-made preparation of the powder and the mixed excipient in the tablet may account for this unsatisfactory result. In the present study, we used a commercially-available alendronate powder, which does not contain any excipient mixed. Nonetheless, the fatigue life of APAC decreased by a much smaller margin compared to the case when tablet-ground alendronate powder was used [13].

We immersed all the specimens in PBS, at $37^{\circ} \mathrm{C}$, for 30 days to simulate the physiological environment [16]. The mechanical strength after immersion changed due to two effects: the aging effect increased the strength in the early time and the plasticization effect of PBS uptake decreased the strength in the late time [16]. In our study, all the specimens were tested after 30 days' standing to mitigate the aging effect as far as possible. Quasi-static mechanical properties decreased after PBS immersion, suggesting that the plasticization effect might play an important role.

Three study limitations are recognized. First, porosity was determined using SEM. A 3D technique, such as micro-computed tomography, may provide a more reliable and precise evaluation of number, size, and distribution of pores in bone cement than SEM [28]. Second, the fatigue tests were conducted at only one stress level $( \pm 15 \mathrm{MPa})$; as such, fatigue limits of the cements were not determined. Third, the specimens were prepared using hand-mixed, instead of vacuum mixed, cement [13]. It has been suggested that vacuum mixing decreases porosity and increases fatigue life of an acrylic bone cement [29]. However, Macaulay et al. [30] found that hand mixing by skilled technicians did not result in negative effects on cement porosity. Hence, hand mixing is thought to be reliable and reproducible [29, 30].

In conclusion, we found that adding a commercially-available alendronate powder to an acrylic bone cement (APAC) did not significantly affect any of the quasi-static mechanical properties of the cement determined but significantly decreased the fatigue life of the cement, which may be a consequence of the significant increase in porosity. Thus, clinical use of APAC cannot be recommended. Future work will investigate reinforcement of APAC with additives, such as bioceramic fibers [31], as means of increasing the fatigue life of the cement.

\section{Acknowledgments}

This work was supported by the National Natural Science Foundation of China (81472113).

\section{Abbreviations}

APAC: acrylic bone cement loaded with alendronate powder

PBS: phosphate buffered saline

ASTM: American Society for Testing and Materials

ISO: International Standardization Organization SEM: scanning electron microscope

\section{Competing Interests}

The corresponding author has the right to grant on behalf of all authors and does grant on behalf of all authors, a worldwide license to the Publishers and its licensees in perpetuity, in all forms, formats and media (whether known now or created in the future), to i) publish, manuscript reproduce, distribute, display and store the Contribution, ii) translate the Contribution into other languages, create adaptations, reprints, include within collections and create summaries, extracts and/or, abstracts of the Contribution, iii) create any other derivative works based on the Contribution, iv) to exploit all subsidiary rights in the Contribution, v) the inclusion of electronic links from the Contribution to third party material where-ever it may be located; and, vi) license any third party to do any or all of the above.

The authors have declared that no competing interest exists.

\section{References}

1. Abu-Amer Y, Darwech I, Clohisy JC. Aseptic loosening of total joint replacements: mechanisms underlying osteolysis and potential therapies. Arthritis Res Ther. 2007; 9: S6.

2. Jones RE, Russell RD, Huo MH. Alternatives to revision total knee arthroplasty. J Bone Joint Surg Br. 2012; 94: 137-40.

3. Lin T, Yan SG, Cai XZ, et al. Bisphosphonates for periprosthetic bone loss after joint arthroplasty: a meta-analysis of 14 randomized controlled trials. Osteoporos Int. 2012; 23: 1823-34.

4. Papapetrou PD. Bisphosphonate-associated adverse events. Hormones 2009; 8: 96-110.

5. Inderjeeth CA, Glendenning P, Ratnagobal S, et al. Long-term efficacy, safety, and patient acceptability of ibandronate in the treatment of postmenopausal osteoporosis. Int J Womens Health. 2014; 7: 7-17.

6. Hamish S, Nick A, Ashley Y. Bisphosphonate cement composition to prevent aseptic loosening of orthopedic implant devices. Patent WO9639107. 1996.12.12.

7. Lewis G. Fatigue testing and performance of acrylic bone-cement materials: state-of-the-art review. J Biomed Mater Res B Appl Biomater. 2003; 66: 457-86.

8. Zwolak P, Manivel JC, Jasinski P, et al. Cytotoxic effect of zoledronic acid-loaded bone cement on giant cell tumor, multiple myeloma, and renal cell carcinoma cell lines. J Bone Joint Surg Am. 2010; 92: 162-8. 
9. Healey JH, Shannon F, Boland P, et al. PMMA to stabilize bone and deliver antineoplastic and antiresorptive agents. Clin Orthop Relat Res. 2003; 415(Suppl): S263-75.

10. Zhu FB, Cai XZ, Yan SG, et al. The effects of local and systemic alendronate delivery on wear debris-induced osteolysis in vivo. J Orthop Res. 2010; 28: 893-9.

11. Mazurkiewicz T, Matuszewski L, Matuszewska A, et al. Implanted bisphosphonates in bone cement affect bone markers in rat serum. Int Orthop. 2013; 37: 969-74.

12. Yu NY, Ruys AJ, Zenios M, et al. Bisphosphonate-laden acrylic bone cement: mechanical properties, elution performance, and in vivo activity. J Biomed Mater Res B Appl Biomater. 2008; 87: 482-491.

13. Lewis $G$, Janna S. Alendronate in bone cement: fatigue life degraded by liquid, not by powder. Clin Orthop Relat Res. 2006; 445: 233-8.

14. Matuszewski $€$, Olchowik G, Mazurkiewicz T, et al. Biomechanical parameters of the BP-enriched bone cement. Eur J Orthop Surg Traumatol. 2014; 24: 435-41.

15. Song D, Ni J, Mao X, Ding M. Effect of alendronate amount on the quasi-static mechanical properties of bone cement. Zhong Nan Da Xue Xue Bao Yi Xue Ban. 2014; 39: 178-84.

16. Nottrott M. Acrylic bone cements: influence of time and environment on physical properties. Acta Orthopaedica. 2010; 81(Suppl): 1-27.

17. ASTM F451-99a Standard Specification for Acrylic Bone Cement. ASTM International, West Conshohocken, PA, USA, 2014, available at www.astm.org DOI:10.1520/F0451-99AR07E01.

18. International Organization for Standardization. ISO 527-1:2012. Available at https://www.iso.org/standard/56045.html.

19. International Organization for Standardization. ISO 5833:2012. Available at https://www.iso.org/standard/30980.html..

20. ASTM Standard No. F 2118-01a: Medical Devices and Emergency Medical Devices. In: American Society for Testing and Materials (ASTM) eds. 2002 Annual Book of ASTM Standards. Vol. 13.01. West Conshohocken, PA, USA: ASTM; 2002:1673-1680.

21. Shigley JE, Mischke CR, Budynas RG. Mechanical Engineering Design, 7th edition. New York, NY, USA: McGraw-Hill; 2004.

22. Britton JC, McInnes P, Ledoux WR, Retief DH. Shear bond strength of ceramic orthodontic brackets. Am J Orthod Dent Orthop. 1990; 98: 348-53.

23. Lewis G, Janna S, Carroll M. Effect of test frequency on the in vitro fatigue life of acrylic bone cement. Biomaterials. 2003; 24: 1111-7.

24. Hoey DA, Taylor D. Statistical distribution of the fatigue strength of porous bone cement. Biomaterials. 2009; 30: 6309-17.

25. Kuehn KD, Ege W, Gopp U. Acrylic bone cements. mechanical and physical properties. Orthop Clin North Am. 2005; 36: 29-39.

26. Topoleski LD, Ducheyne P, Cuckler JM. Microstructural pathway of fracture in poly(methyl methacrylate) bone cement. Biomaterials. 1993; 14: 1165-72.

27. Jeffers JR, Browne M, Roques A, Taylor M. On the importance of considering porosity when simulating the fatigue of bone cement. J Biomech Eng. 2005; 127: 563-70.

28. Cox BD, Wilcox RK, Levesley MC, Hall RM. Assessment of a three-dimensional measurement technique for the porosity evaluation of PMMA bone cement. J Mater Sci Mater Med. 2006; 17: 553-7.

29. Dunne NJ, Orr JF, Mushipe MT, Eveleigh RJ. The relationship between porosity and fatigue characteristics of bone cements. Biomaterials. 2003; 24: $239-45$.

30. Macaulay W, DiGiovanni CW, Restrepo A, Saleh KJ, Walsh H, Crossett LS, Peterson MG, Li S, Salvati EA. Differences in bone-cement porosity by vacuum mixing, centrifugation, and hand mixing. J Arthroplasty. 2002; 17: 569-75.

31. Zhou Y, Yue W, Li C, Mason JJ. Ouasi-static and fatigue mechanical characterizations of variable diameter fibers reinforced bone cement. J Mater Sci Mater Med. 2009; 20: 633-41. 